Table 3

\begin{tabular}{|c|c|c|c|c|}
\hline $\begin{array}{c}\text { Part of } \\
\text { Retina } \\
\text { Receiving } \\
\text { Stimulation } \\
\end{array}$ & $\begin{array}{l}\text { Simulation } \\
\text { Arriving in }\end{array}$ & $\begin{array}{c}\text { Two- } \\
\text { Handed } \\
\text { Responding } \\
\end{array}$ & $\begin{array}{c}\text { Single- } \\
\text { Handed } \\
\text { Responding }\end{array}$ & $\begin{array}{c}\text { Difference } \\
\text { Two Handed } \\
\text { Minus Single } \\
\text { Handed }\end{array}$ \\
\hline Nasal & $\begin{array}{l}\text { Right Hemisphere } \\
\text { Left Hemisphere }\end{array}$ & $\begin{array}{l}268.35 \\
273.34\end{array}$ & $\begin{array}{l}233.70 \\
238.96\end{array}$ & $\begin{array}{l}34.65 \\
34.38\end{array}$ \\
\hline Temporal & $\begin{array}{l}\text { Right Hemisphere } \\
\text { Left Hemisphere }\end{array}$ & $\begin{array}{l}252.94 \\
260.03\end{array}$ & $\begin{array}{l}216.65 \\
224.23\end{array}$ & $\begin{array}{l}36.29 \\
36.80\end{array}$ \\
\hline
\end{tabular}

finding of Cernacek (1961). Using the technique of stimulating a point of the cerebral cortex in one hemisphere and observing the response in the symmetrical point of the contralateral cerebral cortex, he observed that when the symmetrical point is in a motor area, then a facilitation in the contralateral hemisphere may be observed as a lowering of the threshold of its excitability. On the basis of his evidence, Cernacek concluded that crossed motor irradiation occurs more frequently from the dominant than from the subordinate extremity, suggesting some superiority of motor cortex functioning in the left hemisphere.

One other aspect of the results worthy of comment is the finding that two-handed responding is markedly and consistently slower than single-handed responding. Table 3 summarizes the results and compares RTs for the right-handed Ss, depending upon whether only one hand or both hands are responding. Whether the comparison is made under the nasal or temporal stimulation condition, the difference is still appreciable. Specifically in the case of nasal retinal stimulation arriving first in the right hemisphere, two-handed responding is $34.65 \mathrm{msec}$ slower than single-handed responding, and when it arrives first in the left hemisphere, the difference is $34.38 \mathrm{msec}$. For temporal nasal stimulation the corresponding differences are $36.29 \mathrm{msec}$ and $36.80 \mathrm{msec}$, respectively. The finding that it takes more time to mobilize and initiate a response with two hands than with one is not surprising. However, with such very highly practiced $S$ s the amount of extra time required seems, subjectively at least, right.

\section{REFERENCES}

ARUTIUNOVA, A. S., \& BLINKOV, S. M. Latent period of motor reaction with hemianopia. Journal of Higher Nervous Activity, 1962, 12, 432.436.

CERNACEK, J. Contralateral motor irradiation-cercbral dominance. Archives of Neurology, 1961, 4, 165-172.

EFRON, R. The effect of handedness on the perception of simultaneity and temporal order. Brain, 1963, 86, 261-284

JEEVES, M. A. Psychological studies of three cases of congenital agenesis of the corpus callosum in man. In CIBA Foundation Study Group No. 20 (Eds.), Functions of the corpus callosum. London: Churchill, 1965. Pp. 73-94.

JEEVES, M. A. A comparison of interhemispheric transmission times in acallosals and normals. Psychonomic Science, 1969. 16, 245-246.

KERR, M., MINGAY, R., \& ELITHORN, A Cerebral dominance in reaction time responses. British Journal of Psychology, 1963, 54, 325-336.

MOSKATOVA, A. K. Simple motor reaction time to tactile stimulation. Voprosy Psikhologii, 1966, 2, 68-74.

POFFENBERGER, A. T. Reaction time to retinal stimulation with special reference through nerve centres. Archives of Psychology, $1912,23,1$. surprisingly long, and the finding would seem to warrant further study in its own

\title{
Effects of degree of interpolated learning on the recall of first-list responses at two retention intervals
}

\author{
ERNEST H. LeMAY* \\ Plattsburgh State University College, Plattsburgh, N.Y. 12901
}

This study investigated the effects of degree of IL learning on the retention of the responses in paired-associate learning. There were eight groups formed from the factorial arrangement of two retention intervals (immediate and $24 \mathrm{~h}$ ) and of four levels of number of IL trials $(0,2,4$, and 6$)$. The results showed that in the immediate-recall condition response recall was poorest when IL was present, although degree of IL was not significant. There was no effect of IL trials when the retention interval was at $24 \mathrm{~h}$.

Barnes \& Underwood (1959) used the modified modified free recall (MMFR) technique to study the effects of degree of interpolated learning (IL) in an $A-B, A-C$ paradigm. Using a "lenient" scoring procedure, they found that as the number of IL trials increased, the Ss recalled fewer first-list responses (B). In this study, it was possible that Ss knew the responses but withheld these when they could not pair them with the correct stimulus. Goggins (1963) showed that if a $\mathrm{S}$ knew a response, he was able to pair it correctly with its stimulus. In her study, Goggins did not vary the number of IL trials; and in both her experiment and the Barnes and Underwood-study, only a single retention interval was used.

The present study investigated the effects of number of IL trials on the recall of the responses in an $\mathrm{A}-\mathrm{B}, \mathrm{A}-\mathrm{C}$ paradigm over two retention intervals.

$$
\text { METHOD }
$$

The $120 \mathrm{Ss}$ used in this study were undergraduate students at Plattsburgh State University College who participated in the experiment to fulfill a course requirement.

Two paired-associate (PA) lists, based on the $A-B, A-C$ paradigm containing 12 pairs, were constructed. The stimuli were CVCs selected from Noble's (1961) list and varied in $\mathrm{m}^{\prime}$ from 3.02 to 3.22 with a mean value of 3.14 . The 24 responses were AA nouns selected from the Thorndike-Lorge (1944) workbook. The two lists were presented by the method of recall where the pairs are presented first and then followed by the stimuli. The pairs for each list and the stimuli were arranged in four random orders to avoid serial effects. During learning, pairs and stimuli were presented on a screen using two Carousel projectors, one for pair presentation and one for stimuli presentation. The pairs were presented at a 2-sec rate, while the stimuli were presented at a $3-\mathrm{sec}$ rate to allow the Ss time to write down the correct responses to each stimulus. The responses were written in two booklets, one for each list, provided to the Ss. These booklets contained four pages on which the numbers 1.12 were printed in a column. Each stimulus, when presented, was accompanied by numbers from 1 to 12 , in that order. The Ss' responses were written next to the number in the booklet corresponding to the number accompanying the stimulus. Although the order of the numbers never changed, the

\footnotetext{
* The writer wishes to thank Larry Buchanan, Paul Kopita. and Shaun Seymour for their help in running the $S s$ and in analyzing the data.
} 
presentation of the stimuli was randomized; hence, there was no consistent pairing of stimulus and number.

The Ss were read the usual PA instructions with the exception that they were told that a trial consisted of the presentation of all the pairs followed by all the stimuli, and further that when the stimuli were presented they were to try to write the correct response in their booklets.

There were eight groups of 15 Ss each, resulting from the factorial combination of four levels of IL learning and two levels of the retention interval. The learning of the first list was carried to four trials while the second or IL list was learned for $0,2,4$, or 6 trials, depending on the condition the $S$ was in. To equate for the differential times in learning the last list, a filler task was used that consisted of a brief demonstration on how to solve the "pyramid" puzzle. Recall was approximately $7 \mathrm{~min}$ (immediate) after List 1 learning or $24 \mathrm{~h}$ later. The Ss were assigned to the conditions on a random basis and were run in groups. Within a particular number-of-trials condition, both retention groups were run simultaneously during learning, the only difference being the retention interval. Due to limitations in room size, approximately one-half of the Ss in each condition were run during one week while the other half during the following week. The order of the number-of-trials condition was randomized in both instances.

The recall task consisted in giving the Ss blank sheets of paper and instructing them to write all the responses (words) that they could think of regardless of order or list membership. The Ss were cautioned not to write the stimuli.

\section{RESULTS}

A 2 by 3 analysis of variance was carried out on List 1 total correct anticipation (TCA) to test for group equivalence. The results of this analysis showed no significant $F S$ for the number-of-trials variable, $F(3,112)=.35, p>.05$, for the retention variable, $\mathrm{F}(1,112)=.32, \mathrm{p}>.05$, and for the interaction between the two, $F(3,112)=.46, p>.05$.

\section{Response Recall of List 1}

The results of this part of the study are presented in Table 1, which shows that

Table 1

Mean Response Recall Scores

\begin{tabular}{lccccc}
\hline Number of IL Trials & 0 & 2 & 4 & 6 \\
\hline Immediate & $\overline{\mathrm{X}}$ & 9.53 & 7.47 & 6.27 & 6.40 \\
Recall & $\mathrm{S}$ & 2.00 & 1.81 & 2.96 & 3.05 \\
$24-\mathrm{h}$ & $\overline{\mathrm{X}}$ & 6.87 & 7.33 & 6.87 & 6.60 \\
Recall & $\mathrm{S}$ & 1.69 & 2.55 & 2.39 & 2.75 \\
\hline
\end{tabular}

under the shorter retention interval as the number of trials on IL increased the response recall decreased to about the four-trial condition and then leveled off. Recall after $24 \mathrm{~h}$ appears to be about equal for all groups. An analysis of variance was performed on these data and revealed a nonsignificant retention-interval effect, $F(1,112)=1.28, p>.05$. A trend analysis was carried on the number-of-trials variable, which resulted in a significant linear effect, $F(1,112)=9.01, p<.01$. The linear component of the Retention by Trials interaction was also significant, $\mathrm{F}(1,112)=5.57, \mathrm{p}<.05$. All other variables were not significant. The data were further analyzed by using Scheffe's test for multiple comparisons. This test showed that the control group in the immediate recall condition was significantly different from the other three groups, $F^{\prime}(3,112)=15.29, p<.05$. None of the other comparisons was significant. The results of this analysis for the 24-h retention scores did not produce any significant comparisons.

Response Recall of List 2

The response recall scores of the second list were also analyzed. The results showed significant Fs for retention interval, $F(l, 112)=8.37, \quad p<.05$, and for the number-of-trials variable, $F(3,112)=13.00, p<.05$. The interaction was not significant. A trend analysis was carried out on these data and showed both a significant linear trend, $F(1,84)=12.99$, $\mathrm{p}<.01$, and a significant quadratic trend, $F(1,84)=13.00, p<.01$. These results showed that as the number of trials increased $S$ s recalled more responses under both retention intervals, and further there was a leveling off of response recall at the higher degree of IL learning. This latter finding could be due to ceiling effects.

\section{DISCUSSION}

Concerning the results of this study, two facts stand out. First, most studies which have varied degree of IL have found that some minimal amount of IL produced maximum interference, e.g., Underwood (1945). Sandak \& Garskof (1967) showed that only high degrees of IL were significantly different from the control group in this type of design. However, these two groups did not differ from one another. Similar findings are reported in this study despite the fact that Sandak and Garskof were measuring $S-R$ associative matching. while the present study is concerned with response recall. Along this line, it is worth mentioning that the studies of Barnes \& Underwood (1959), Sandak and Garskof, and to some extent the present study seem to indicate that increasing the degree of $\mathrm{IL}$ results in a decrease in OL recall scores, but the differences are not significant. Hence, the effect must be small. Secondly, the results of the response recall at $24 \mathrm{~h}$ showed that the number-of-trials variable was not significantly different from the control group's. The reason for this finding may be due to the fact that at $24 \mathrm{~h}$ only the strongest, hence most resistant (to forgetting), items are retained. The IL would then be viewed as eliminating the weakest items when recall was immediate. Thus, it appears that both response recall and S-R associations are interfered with in these designs, but that the effect of the degree of $I L$ is minimal.

\section{REFERENCES}

BARNES, J. M.. \& LINDERWOOD. B. J. Fate of first-list associations in transfer theory. Journal of Experimental Psychology, 1959, 58, 97-105.

GOGGINS, J. Influence of the written recall measure on first-list associations. Joumal of Experimental Psychology, 1963, 65, 619-620.

NOBLE, C. E. Measurement of association value (a) rated associations, $\left(a^{r}\right)$ and scaled meaningfulness $\left(\mathrm{m}^{\prime}\right)$ for the 2100 CVC combinations of the English alphabet. Psychological Reports, 1961, 3 (Monograph Supplement, Vol. 8).

SANDAK, J. M., \& GARSKOF, B. E. Associative unlearning as a function of degree of interpolated learning. Psychonomic Science, 1967, 7, 215-216.

THORNDIKE, E. L., \& LORGE, I. The teacher's workbook of 30,000 words. New York: Bureau of Publications, Teachers College, Columbia University, 1944.

UNDERWOOD, B. J. The effect of successive interpolations on retroactive and proactive inhibition. Psychological Monographs, 1945, 59 (Whole No. 273). 